\title{
Three-Phase Induction Motor DTC-SVPWM Scheme with Self-tuning PI-Type Fuzzy Controller
}

\author{
Hongxia $\mathrm{Yu}^{1 *}$, Zhicheng Chen ${ }^{2}$ \\ ${ }^{1}$ School of Information Science and Engineering, Shenyang University of Technology, Shenyang, China. \\ ${ }^{2}$ Department of Control Theory and Control Engineering, Shenyang University of Technology, China. \\ * Corresponding author. Tel:18624047512; email: hongxia7512@163.com \\ Manuscript submitted July 10, 2014; accepted January 19, 2015.
}

doi: 10.17706/ijcce.2015.4.3.204-210

\begin{abstract}
The DTC-SVPWM scheme is a kind of high performance control scheme of induction motor drives to improve the high torque ripple drawback of conventional DTC. SVPWM has two PI controllers which are used to generate the reference stator voltage vector. However it is difficult to adjust the parameters of PI controller due to the complexity of the control system. The self-tuning PI fuzzy controller was proposed to adjust the PI parameters in this paper. Two inputs of the fuzzy controller are torque or flux error and error change rate. Correction coefficients of proportional and integral are outputs. The simulation results show that the proposed method can significantly reduce the torque ripple and is suitable for various motor at different working state.
\end{abstract}

Key words: DTC, fuzzy controllers, induction motor drive, SVPWM.

\section{Introduction}

Among all control methods for induction motor drives (IMD), direct torque control seems to be particularly interesting being independent of machine rotor parameters. In the last years DTC has become a popular technique for three-phase IMD as it provides a fast dynamic torque response and robustness under machine parameter variations without the use of current regulators [1]-[3]. The major disadvantage of the DTC drive is the steady state ripples in torque and flux [4]. A torque ripple analysis since none of the inverter switching vectors is able to generate the exact stator voltage required to produce the desired changes in torque and flux, torque and flux ripples compose a real problem in DTC induction motor drive [5]. The most common solution to this problem is to use space vector modulation depends on the reference torque and flux. In DTC-SVPWM, the PI controllers substitute by the hysterics comparators [6]. A fast torque response with low torque ripple for this SVM-DTC is significantly improved with a constant switching frequency compare to classical DTC In [7] proposes a neuro-fuzzy based SVM technique for voltage source inverter and its performance is compared with the conventional based SVM and Neural Network based SVM methods. This scheme is five-layer network, receives the d-axis and q-axis voltages information at the input side and generates the duty ratios as an output for the inverter circuit. In [8] the fuzzy PI speed controller has a better response for a wide range of motor speed. In [9] it is designed a Takagi-Sugeno fuzzy controller to substitute flux and torque PI controllers in a conventional DTC-SVM scheme. Flux error after fuzzy controller generates d axis component of the reference voltage vector, torque error after PI regulator generates q axis component of the reference voltage vector, fuzzy control is widely used in direct torque control system, and the superiority of its robust has been showed in [10]. 
In this paper an adaptive fuzzy PI controller along with the SVPWM technique is applied to inverter. Fuzzy PI controller is used to achieve precision torque control and minimize torque ripple. When fuzzy logic is used for the on-line tuning of the PI controller, it receives fuzzy values of the torque error and change of torque error. Its output is updating in the PI controller gains based on a set of rules to maintain excellent control performance. The proposed technique is simulated in simulink to validate the performance of the algorithm.

\section{Basic Control Principles}

\subsection{DTC-SVPWM Principles}

The proposed DTC-SVPWM system is shown in Fig. 1. Three PI controllers are used for processing speed, torque and flux errors. Speed error is processed through the speed PI controller to generate torque reference.

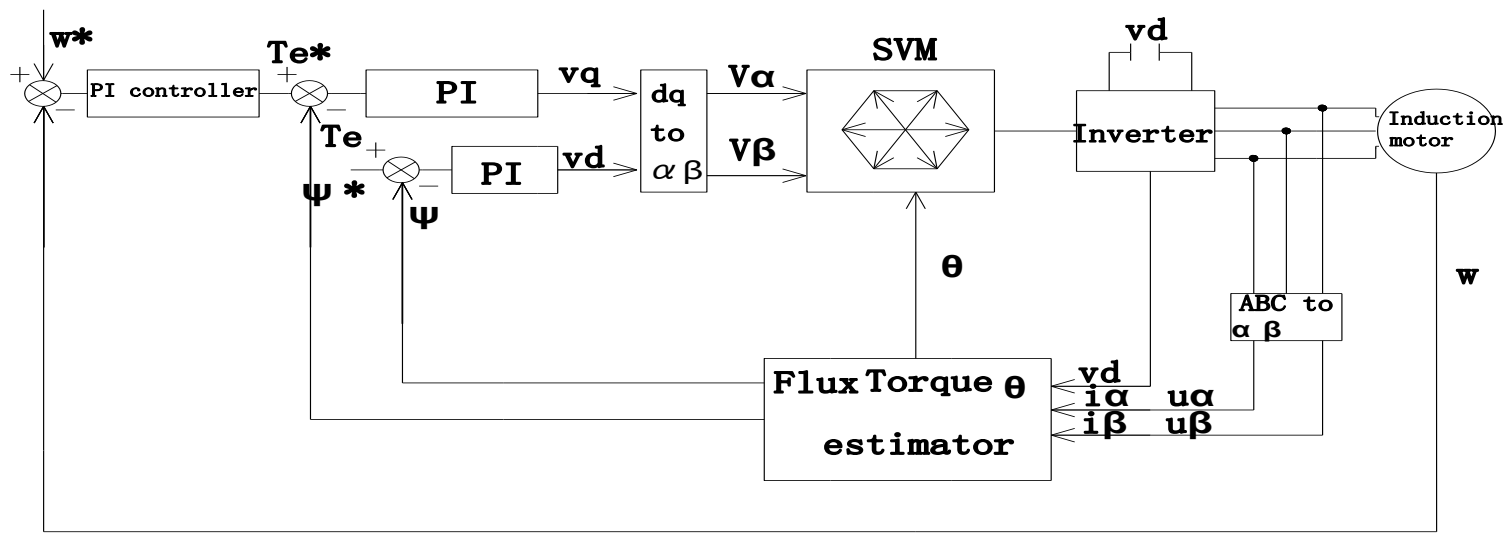

Fig. 1. Proposed DTC-SVPWM model.

The role of torque and flux PI controllers is to generate the command voltages $U_{d}$ and $U_{q}$ respectively. Induction motor stator flux is not easy to measure directly, so we measure voltage and current values of stator side to obtain the value of the stator flux. It calculates the value of estimated electromagnetic torque $T e$ using (1). After calculating $\varphi$ and $T e$, they are compared with their reference values $\varphi^{*}$ and $T e^{*}$ respectively. The controllers generate the components of command voltage in a synchronous reference frame aligned to the stator flux. SVPWM unit receives the command voltage and impress the desired voltages to the motor using a voltage source inverter. In the synchronous reference frame voltage equations can be written as (2) and (3). The output of the PI flux and torque controllers can be interpreted as the reference stator voltage components $U_{d}, U_{q}$ are the stator flux oriented coordinates $(d-q)$, converted these $d-q$ coordinate components to $\alpha$ - $\beta$ components (4).

$$
\begin{gathered}
T e=\frac{2}{3} p\left(\varphi_{s \alpha} i_{s \beta}-\varphi_{s \beta} i_{s \alpha}\right) \\
U_{d}=\left(K_{P \varphi}+\frac{K_{I \varphi}}{S}\right)\left(\varphi_{S}^{*}-\varphi_{S}\right) \\
U_{q}=\left(K_{P T}+\frac{K_{I T}}{S}\right)\left(T_{e}^{*}-T_{e}\right)
\end{gathered}
$$




$$
\left[\begin{array}{l}
U_{\alpha} \\
U_{\beta}
\end{array}\right]=\left[\begin{array}{cc}
\cos \theta & -\sin \theta \\
\sin \theta & \cos \theta
\end{array}\right]\left[\begin{array}{l}
U_{d} \\
U_{q}
\end{array}\right]
$$

\subsection{SVPWM Calculation Unit}

The accuracy in calculation of $U_{d}, U_{q}$ is very important as they are used to generate inverter gating pulses such that direct torque and flux control for the induction motor drive achieved with minimum torque ripple [11]. SVPWM need to know the reference voltage vector in which sector, in order to use the adjacent basic voltage vector to synthesis. According to a given reference voltage component $U_{\alpha}, U_{\beta}$, using Table 1 we can determine $U_{\text {ref }}$ the number of sector.

Table 1. Sector Number and SVPWM Switching Time

\begin{tabular}{|c|c|c|c|c|c|c|}
\hline$N$ & 1 & 2 & 3 & 4 & 5 & 6 \\
\hline Sector & II & VI & I & IV & III & V \\
\hline$T_{1}$ & $\mathrm{Y}$ & $-\mathrm{X}$ & $\mathrm{Z}$ & $-\mathrm{Y}$ & $-\mathrm{Z}$ & $\mathrm{X}$ \\
\hline$T_{2}$ & $-\mathrm{X}$ & $\mathrm{Z}$ & $\mathrm{Y}$ & $-\mathrm{Z}$ & $\mathrm{X}$ & $-\mathrm{Y}$ \\
\hline
\end{tabular}

Fig. 2 shows the space vectors and sector definition [12]. DC bus voltage of the inverter is $U_{d c}$, the sampling period is $T_{S}$. For SVPWM, the reference voltage vector is $U_{\text {ref }}$ which rotates at an angular velocity, is synthesized by time averaging of two adjacent basic non- zero voltage vectors that form the sector plus zero voltage vectors around them. Fig. 1 shows the formation of $U_{\text {ref }}$ (5) using time averaged adjacent non zero space vector in Sector I. It represents the two-level inverter circuit and its space vector diagram with eight different switching states $\left(U_{0}-U_{7}\right)$. The voltage value is zero when the vectors $U_{0}$ and $U_{7}$ are considered. By selecting the remaining six voltage vectors an effective voltage can be applied to the machine.

$$
\int_{0}^{T_{S}} U_{r e f} d t=\int_{0}^{T_{0}} U_{0} d t+\int_{T_{0}}^{T_{0}+T_{1}} U_{1} d t+\int_{T_{0}+T_{1}}^{T_{0}+T_{1}+T_{2}} U_{2} d t+\int_{T_{0}+T_{1}+T_{2}}^{T_{S}} U_{7} d t
$$

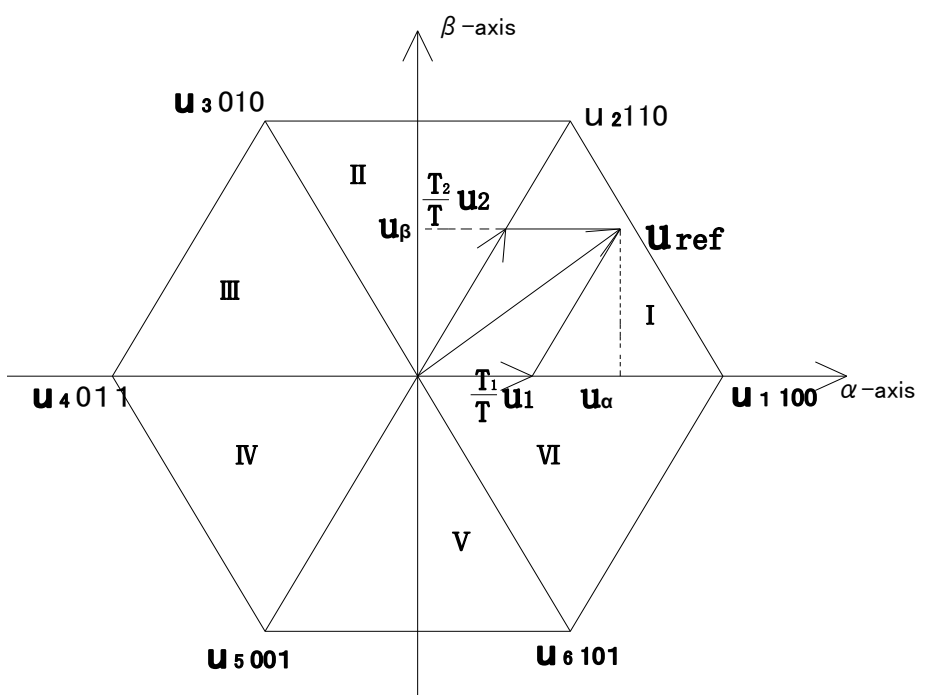

Fig. 2. Voltage vectors of a two-level voltage source inverter and the corresponding switching states. 


\section{Design of Fuzzy PI Controller}

In this section DTC-SVPWM strategy is proposed using modified fuzzy logic controllers. In order to improve direct torque control system dynamic and static performance, the torque and flux is adjusted by the adaptive fuzzy PI controller. The structure of torque and flux controller is the same, so we only specify the torque controller. According to the analysis of step-response in DTC system, four fields of the fuzzy variables could be defined as following. The field of the motor torque feedback error $E_{T}$ is [-3, 3], the field of torque error variation $\Delta E$ is $[-3,3]$, and the field of value $\Delta k p, \Delta k i$ is $[-3,3]$. The input membership functions use Gaussian functions, output membership functions use triangular functions. Error and rate of error change is inconsistent with the scope of the fuzzy controller field, so we use conversion factors transforming them into the field of the standard variable. $k p, k i$ are the adjusted proportional and integral value, $k p^{\prime}, k i^{\prime}$ are the initial choice of proportional and integral value, $\Delta k p, \Delta k i$ is proportional and integral correction factors. All the fuzzy subsets are $\{\mathrm{NB}, \mathrm{NM}, \mathrm{NS}, \mathrm{ZE}, \mathrm{PS}, \mathrm{PM}, \mathrm{PB}\}$. The abbreviations, NB, NM, NS, ZE, PS, PM, PB, represent the negative big, negative small, negative medium, zero, positive small, positive medium, and positive big, respectively. Each rule of the fuzzy controller can be described with $E_{T}, \Delta E, \Delta k p$ and $\Delta k i$. As shown in Table 1, if $E_{T}=\mathrm{NB}$ and $\Delta E=\mathrm{NB}$, then $\Delta k p=\mathrm{PB}$ and $\Delta k i=\mathrm{NB}$. There are 49 rules with two input variables. The fuzzy control rules are expressed in Table 2 and Table 3.

Table 2. Fuzzy Logic Control Rules of $\Delta k p$

\begin{tabular}{|l|l|l|l|l|l|l|l|}
\hline \begin{tabular}{|l|l|} 
E \\
NB
\end{tabular} & NB & NM & NS & ZO & PS & PM & PB \\
\hline NM & PB & PB & PM & PM & PS & ZO & ZO \\
\hline NS & PM & PM & PM & PS & ZO & NS & NS \\
\hline ZO & PM & PM & PS & ZO & NS & NM & NM \\
\hline PS & PS & PS & ZO & NS & NM & NM & NM \\
\hline PM & PS & ZO & NS & NM & NM & NB & NB \\
\hline PB & ZO & ZO & NM & NM & NB & NB & NB \\
\hline
\end{tabular}

Table 3. Fuzzy Logic Control Rules of $\Delta k i$

\begin{tabular}{|l|l|l|l|l|l|l|l|}
\hline \multicolumn{1}{|c|}{ E } & NB & NM & NS & ZO & PS & PM & PB \\
\hline NB & NB & NB & NM & NM & NS & ZO & ZO \\
\hline NM & NB & NB & NM & NS & NS & ZO & ZO \\
\hline NS & NB & NM & NS & NS & ZO & PS & PS \\
\hline ZO & NM & NM & NS & ZO & PS & PM & PM \\
\hline PS & NM & NS & ZO & PS & PS & PM & PB \\
\hline PM & ZO & ZO & PS & PS & PM & PB & PB \\
\hline PB & ZO & ZO & PS & PM & PM & PB & PB \\
\hline
\end{tabular}

\section{Simulation Results}

We used different dynamic operating conditions such as: no load sudden change in the speed reference (from $0 \mathrm{~s}$ to $1 \mathrm{~s}$ ), step change in the motor load (from time $1.6 \mathrm{~s}$ to $2.5 \mathrm{~s}$ ). From time $1.0 \mathrm{~s}$ to $1.6 \mathrm{~s}$ the reference torque is $800 \mathrm{Nm}$, from time $1.6 \mathrm{~s}$ to $2.0 \mathrm{~s}$ the reference torque is $1000 \mathrm{Nm}$, from time $2.0 \mathrm{~s}$ to $2.5 \mathrm{~s}$, 
the motor reference torque is $600 \mathrm{Nm}$. Here generated torque is always follows reference torque, at this time induction motor speed is follow as reference speed $(500 \mathrm{r} / \mathrm{min})$, it shows in Fig. 3. All the test results showed the good performance of the proposed DTC-SVM scheme with fuzzy PI controllers. In Fig. 3(a) it can be seen that the speed returns to its reference quickly when the external load changes, exhibiting strong robustness against external load disturbance and minimizing torque ripple.

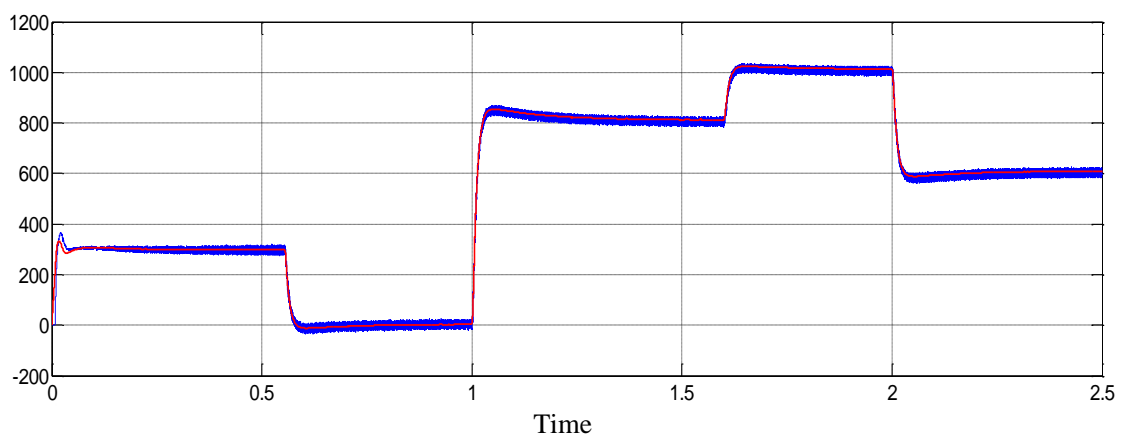

(a)

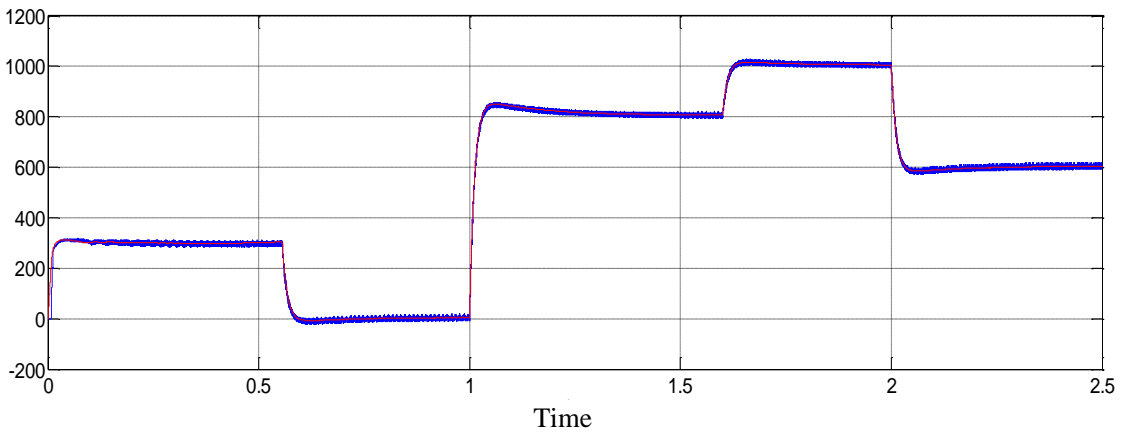

(b)

Fig. 3. (a) Results of electromagnetic torque (149.2KW motor) of classical DTC-SVPWM. (b) Electromagnetic torque of DTC-SVPWM with fuzzy PI controllers.

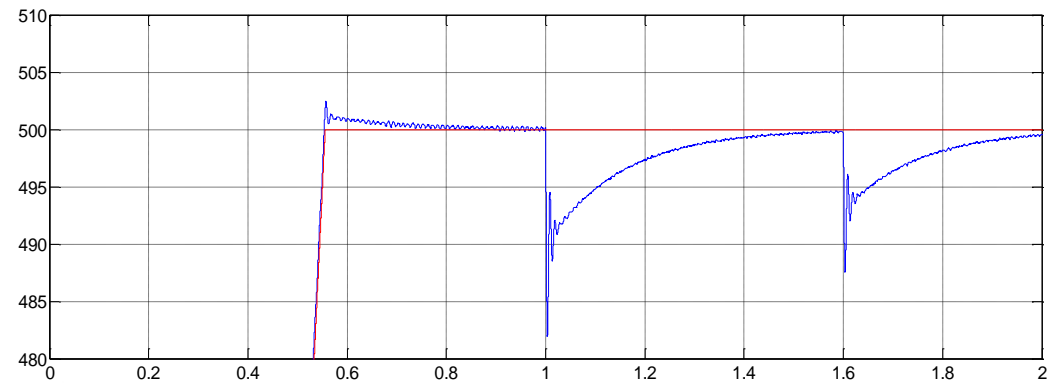

(a)

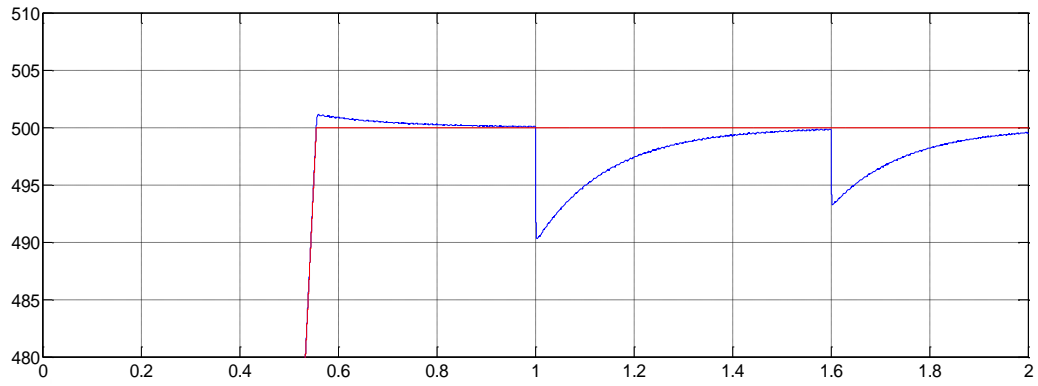

(b)

Fig. 4. (a) DTC-SVPWM system using 37KW motor (speed). (b) Self-tuning PI fuzzy controller with DTC-SVPWM system using 37KW motor (speed). 
We use a 37KW motor to test the performance of the self-tuning PI fuzzy controller with DTC-SVPWM system. The speed is follow as reference speed $(500 \mathrm{r} / \mathrm{min})$. From time $1.0 \mathrm{~s}$ to $1.6 \mathrm{~s}$ the reference torque is $300 \mathrm{Nm}$, from time $1.6 \mathrm{~s}$ to $2.0 \mathrm{~s}$ the reference torque is $500 \mathrm{Nm}$. From Fig. 4 and Fig. 5, the dynamic and static performance of the self-tuning PI fuzzy controller with DTC-SVPWM system is very good, quickening is better, control accuracy is very high, torque of the fluctuation is very small and the stability is good.

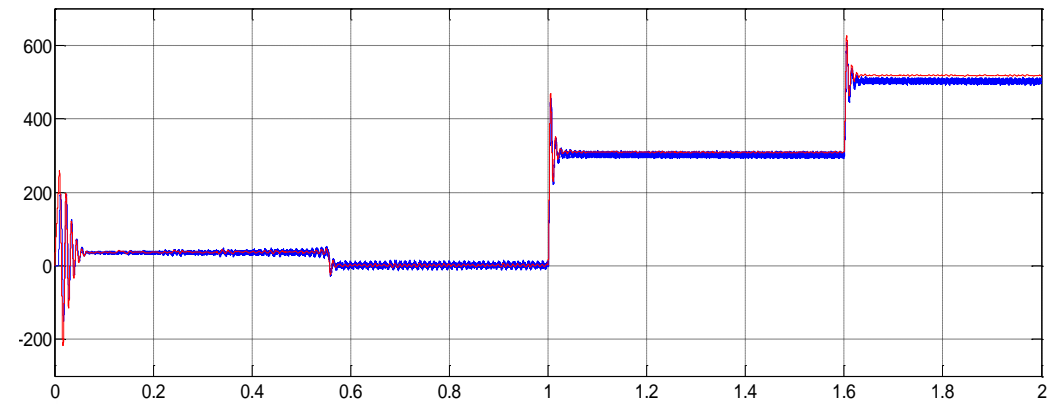

(a)

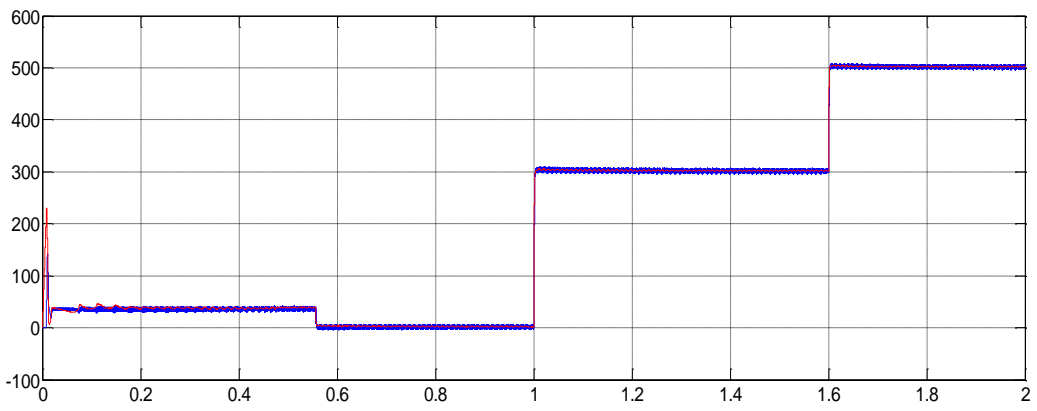

(b)

Fig. 5. (a) DTC-SVPWM system using 37KW motor (torque). (b) Self-tuning PI fuzzy controller with DTC-SVPWM system using 37KW motor (torque).

\section{Conclusion}

The performance of self-tuning PI-type fuzzy controller based DTC-SVPWM is found to be superior to conventional DTC, in terms of torque ripples, transient torque and steady state speed errors. The simulation results show the fast torque response and low torque ripple in a wide range of operating conditions such as step change in the motor load, no-load sudden change in the speed reference.

\section{Acknowledgment}

This work is supported by the Key Laboratory Program of Liaoning Provincial Department of Education (L201211602).

\section{References}

[1] Azcue, J. L., \& Ruppert, E. (Aug. 10-12, 2010). Three-phase induction motor DTC-SVM scheme with self-tuning PI-type fuzzy controller. Proceedings of the Seventh International Conference in Fuzzy Systems and Knowledge Discovery (FSKD): Vol 2. (pp. 757-762). Yantai, Shandong, China.

[2] Lin, G., \& Xu, Z. (April 2010). Direct torque control of induction motor based on fuzzy logic. Proceedings of the 2nd International Conference on Computer Engineering and Technology (ICCET): Vol 4. (pp. 651-654). Chengdu, China.

[3] Benaicha, S. (2013). Novel direct torque fuzzy control of SVM-inverter-fed induction motor drive power 
engineering. Proceedings of the Fourth International Conference on Power Engineering: Energy and Electrical Drives (pp. 340-345).

[4] Jagan, R. M. (2010). DTC-SVM of induction motor with three level diode clamped inverter. Technical and Non technical International Journal VSRD-TNTJ, 1, 178-187.

[5] Jagan, M. R. M., \& Manthi, M. D. (November 2013). Two fuzzy logic controllers based DTC-SVM of induction motor. International Journal of Engineering Research \& Technology, 2(11), 1956-1969.

[6] Belkacem, S., Naceri, F., \& Abdessemed, R. (April 2011). Improvement in DTC-SVM of AC drives using a new robust adaptive control algorithm. International Journal of Control Automation and Systems, 9, 267-275.

[7] Durgasukumar, G., \& Pathak, M. K. (June 2012). Comparison of adaptive neuro-fuzzy-based space-vector modulation for two-level inverter. International Journal of Electrical Power and Energy Systems, 38(1), 9-19.

[8] Toufouti, R., Meziane, S., \& Benalla, H. (June 2006). Direct torque control for induction motor using fuzzy logic. Advances in Ceramic Science and Engineering Journal, 6(2), 265-270.

[9] Jos'e, L., Azcue, P., Alfeu, J., \& Sguarezi, F. E. (2010). Ts fuzzy controller applied to the DTC-SVM scheme for three-phase induction motor. Proceeding of Power Electronics Conference (COBEP) (pp. 201-206). Praiamar, Brazil.

[10] Aimer, A. F., Bendiabdellah, A., \& Miloudi, A. (2009). Application of fuzzy logic for a ripple reduction strategy in DTC scheme of a PWM inverter fed induction motor drives. Journal of Electrical Systems, 1, 13-17.

[11] Subba, R. G. (2013). Vector controller based speed control of induction motor drive with 3-Level SVPWM based inverter. International Journal of Emerging Trends in Electrical and Electronics, 1(4), 1-11.

[12] Sandeep, N. P., Vishal, S. S., \& Akshay, A. P. (2013). Simulation analysis of SVPWM inverter fed induction motor drives. International Journal of Emerging Trends in Electrical and Electronics, 2(4), 18-22.

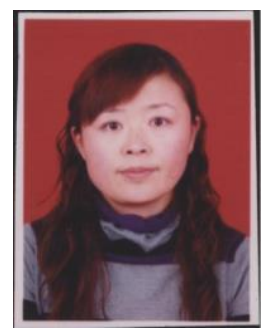

Hongxia Yu was born in Shenyang, Liaoning province, China, in 1975. She received the BSc degree from Liaoning Institute of Technology in 1998, the MSc degree from Northeastern University in 2003. Then she received the PhD degree from Shenyang Institute of Automation, Chinese Academy of Science in 2012. Her fields of interest are state monitor and control of induction motor, etc. She has been as a lecturer in Shenyang University of Technology since 2003.

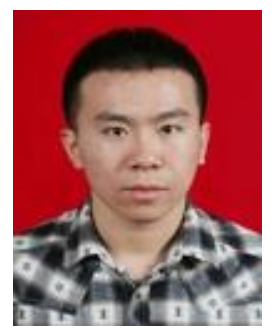

Zhicheng Chen was born in Harbin, Heilongjiang province, China, on April 28, 1988. He received his undergraduate degree in automation from City Institute of Dalian University of Technology, Dalian, China, in 2011. He is currently working toward the master degree at the Shenyang University of Technology, Shenyang, since 2012. His scientific work is related to electrical machines and drives. His current research interest includes direct torque control of induction motors. 